\title{
PROFITABLE CULLING RATES OF BARKI SHEEP FLOCK RAISED UNDER SEMI-ARID CONDITIONS IN EGYPT
}

\author{
Mona I. Mohammady \\ Division of Animal Production and Poultry, Desert Research Center, Matarya, Cairo, Egypt
}

\section{SUMMARY}

The current research was conducted to determine the optimal annual culling rates that maximize profits generated from different Barki sheep flocks varying mainly in biological performance and different annual culling rates raised under semi-arid conditions. Data utilized were obtained from the accumulated 7233 records of Barki sheep flock collected over 37 successive breeding seasons representing 2039 breeding ewes raised at Maryout Research Station. Two variables were combined factorially to create twelve simulated flocks, the first variable was biological performance of three categories, top (T), medium (M) and bottom (B), while the second variable was proposed culling rates with four levels (10\%, 15\%, 20\% and 30\%). Financial comparison among the studied twelve simulated flocks revealed the considerable interrelation between the biological performance of the flock and annual culling rate and its impact on flock profitability. The results showed that simulated flock (T/15) achieved the highest gross margin/ewe of LE 173 among all the studied flocks, except those simulated flocks of (B/10) and (B/30) which scored negative values of LE -12 and LE -43, respectively. The current Benefit/Cost ratios revealed that, simulated flock (T/15) achieved the highest ratio of 1.25, in contrary, the four bottom simulated (B/10, B/15, B/20, B/30), scored 0.98, 1.01, 1.02 and 0.95, respectively. The current research concluded that the recommended profitable annual culling rate for Barki sheep enterprise were $15 \%$ for $(T)$ flock, while 20\% for (M) and (B) flocks raised under semi-arid conditions in Egypt.

\section{Keywords: Barki sheep, culling rate, biological performance, gross margin}

\section{INTRODUCTION}

Increasing profitability of sheep enterprise is the ultimate goal of sheep producers. A fundamental component of enhancing profitability is having the ability to evaluate opportunities for cost control, revenues enhancement and/or maximize the difference between what does it cost to produce lambs for marketing, and what revenues that are received. In this context, most advanced technology and management practices are designed to enhance revenues. One of the most important management practices in a sheep flock is culling rate. Sheep producers that intend to maintain their flocks will need to replace a proportion of the flock each year and it depends on biological performance of the flock and objectives of the producer. Generally, each individual sheep enterprise is unique, because each flock is affected by its own biological performance characteristics. Therefore, annual culling rate differs from one flock to another and based on number of ewes disposed from the flock. Having established how many replacements will be required, the next step is to decide how these are going to be sourced, purchase from the market or self-replacing within the flock.

One of the main component affecting annual culling rate is the available number of ewe lambs reaching joining age per ewe joined (Mohammady, 2005), since this trait is considered as a conclusive biological criterion, combing fecundity, prolificacy as well as lamb's mortality (Turner et al, 1968). Therefore, it is important to determine the biological performance level for operating a profitable sheep enterprise. Few studies are available dealing with the bio-economic impact of changing annual culling rate on profitability of Barki sheep flock under semi-arid conditions in Egypt. The current research was conducted to determine the optimal annual culling rates that maximize profits generated from different simulated Barki sheep enterprises varying mainly in level of biological performance raised under semiarid conditions.

\section{MATERIALS AND METHODS}

\section{Source of data}

Data utilized in the current research were obtained from the accumulated 7233 records of Barki sheep flock. These data were collected over 37 successive breeding seasons, representing 2039 breeding ewes raised at Maryout Research Station. This station belongs to Desert Research Center in Cairo and located in the North West of Nile Delta, some $30 \mathrm{~km}$ South West of Alexandria. This area is classified in the more general sense as a semi-arid area, where the rainfall is very erratic in time and space and high coefficients of variation, indicate that rain amount is very variable from one year to another, with an annual average of 150-180 mm mainly during November - March.

\section{Flock management practices:}

The studied Barki flock was kept in open shed wire-fenced pens. Breeding rams and ewes were selected for mating season according to Barki breed phenotypic characteristics and due to established productive and reproductive criteria. During mating season, breeding ewes were homogeneity distributed 
according to their ages in mating pens $(20-25$ heads/pen) and naturally mated with fertile breeding ram. The mating season lasted for 34 days (two estrous cycles) once a year. Born lambs were kept with their dams during suckling period. Ewe lambs and ram lambs selected for replacement were allowed to join mating season for first time at age of 1.5 years approximately. A regular recording system for flock biological data was performed on a routine basis; at lambing, new born lambs were identified with metal ear tags, their sex, type of birth, birth date, pedigree and animal disposals dates and reasons. Body weight was recorded within 24 hours of birth and bi-weekly until weaning at age of 90 days.

The studied flock was kept under regular feeding regime adopted according to management program and physiological status of the breeding ewes and recommended by NRC (2007). Feed was composed of concentrate feed mixture (CFM) in addition to berseem (Trifolium alexandrinum) as a green fodder during the period from October to May, while the rest of the year, berseem was replaced by berseem hay. Two weeks prior mating season, extra supplementary concentrate feed mixture of about $0.5 \mathrm{~kg} / \mathrm{head} /$ day was offered for flushing the breeding ewes and also during late pregnancy and early lactation periods. Breeding rams were offered the above-mentioned ration, as well as, extra daily $0.5 \mathrm{~kg}$ of barely per head during mating season. The ration was offered once a day and water was available twice daily. Whenever available, the flock was allowed grazing in neighboring areas from sunrise until sunset.

\section{Culling and replacement practices:}

The regular annual culling and replacement procedures of the studied flock were performed twice throughout the production cycle. Firstly, after weaning season to cull breeding ewes according to established criteria namely; barren ewes, cast for age, poor mothering ability, udder conformation, weakness and those with poor wool characteristics. While the replacement procedures performed before mating season to select ewe lambs for replacement according to pedigree, average growth rate and phenotypic characteristics of Barki breed.

\section{Research design:}

To achieve the established goals of the current research, data included three phases of statistical analysis, the first phase was considered as a base run and utilized the original raw data of the 7233 collected cumulative records of the studied flock to have an overview of the biological profile of the studied flock and to derive the least squares means of number of ewe lambs reaching joining age per ewe joined (ELR/EJ) for the studied 37 different breeding seasons. Data in Figure (1) illustrates seasonal variations of ELR/EJ estimates throughout the studied 37 breeding seasons. The figure showed the fluctuations of ELR/EJ estimates that ranged from 0.05 up to 0.33 due to variations in environmental conditions from one breeding season to another.

In the second phase, the obtained least squares means of ELR/EJ of the 37 breeding seasons were ranked according to the estimated values of ELR/EJ in descending order. The ranked estimates were partitioned into three biological performance categories; top (T), medium (M) and bottom (B). The third phase of data analysis was performed after culling and removal of a number of breeding ewes from data of each category according to the proposed annual culling rates $(10 \%, 15 \%, 20$ and $30 \%)$ to determine the biological performance of the flock after applying each proposed culling rate.

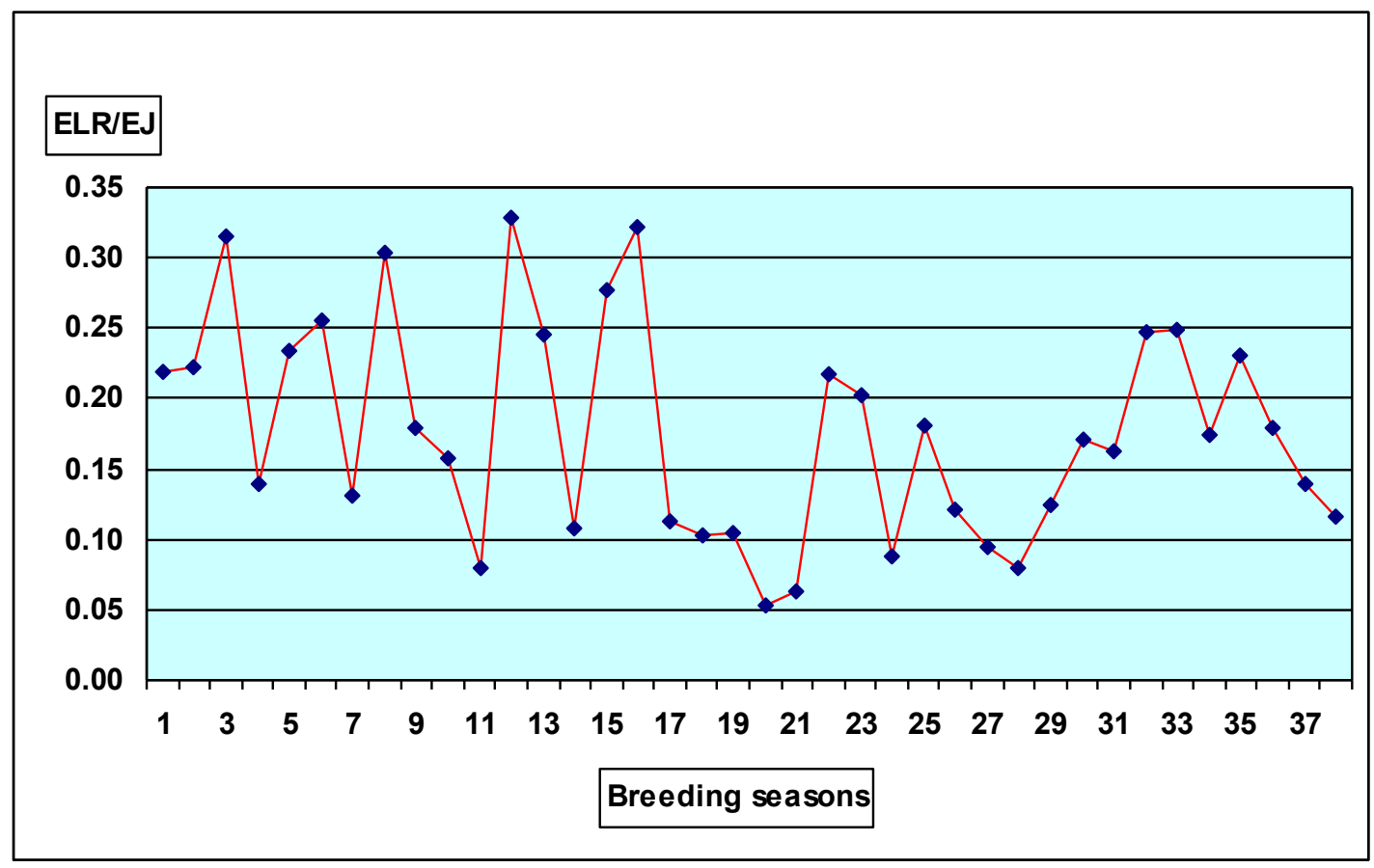

Figure 1. Seasonal variations of number of ewe lambs reaching joining age per ewe joined (ELR/EJ) for the studied breeding seasons 


\section{Statistical analysis}

Least squares procedures as described by SAS (2004) were performed using fixed effect linear model. Two models were used; the first model was considered as a base run to develop least squares estimates of ELR/EJ for the 37 breeding seasons. While the second model was utilized to extract biological estimates for the three biological categories after applying the proposed culling rates. Biological traits considered were; number of ewes lambed per ewe joined (EL/EJ), number of lambs born per ewe joined (LB/EJ), number of lambs weaned per ewe joined (LW/EJ) and (ELR/EJ). The fixed effect linear model used to analyze the (ELR/EJ) trait was as follows;

Where: $\mathrm{Y}_{\mathrm{ij}}=\mu+\mathrm{a}_{\mathrm{i}}+\mathrm{e}_{\mathrm{ij}} \quad \operatorname{Model}(1)$

$\mathrm{Y}_{\mathrm{ij}}=$ the observation,

$\mu=$ the overall mean,

$\mathrm{a}_{\mathrm{i}}=$ effect due to $\mathrm{i}^{\text {th }}$ breeding season, $\mathrm{i}=1$, up to 37 breeding seasons

The fixed effect linear model used to analyze the above mentioned biological traits was as follows;

Where:

$$
\mathrm{Y}_{\mathrm{ijk}}=\mu+\mathrm{a}_{\mathrm{i}}+\mathrm{b}_{\mathrm{j}}+(\mathrm{ab})_{\mathrm{ij}}+\mathrm{e}_{\mathrm{ijk}} \quad \operatorname{Model}(2)
$$

$\mathrm{Y}_{\mathrm{ijk}}=$ the observation,

$\mu=$ the overall mean,

$\mathrm{a}_{\mathrm{i}}=$ effect due to $\mathrm{i}^{\text {th }}$ category, $\mathrm{i}=$ top,

medium and bottom,

$\mathrm{bj}=$ effect due to $\mathrm{j}^{\text {th }}$ culling rate, $\mathrm{j}=10 \%$, $15 \%, 20 \%$, and $30 \%$,

$(a b)_{i j}=$ effect of the interaction between $i^{\text {th }}$ category and $j^{\text {th }}$ culling rate,

$\mathrm{e}_{\mathrm{ijk}}=$ the random effect associated with the individual observation. This element represents all the unidentified factors that may affect the traits under investigation and are not included in the model. Significant differences among biological traits were tested using Duncan's Multiple Rang Test.

\section{Simulated flocks}

Barnard and Nix (1993) reported that simulation technique can be used to investigate the effect of different proposed management practices before implementation on profits of sheep enterprise. Using deterministic simulation tool, an empirical economic study launched to investigate the impact of different proposed culling rates $(10 \%, 15 \%, 20$ and $30 \%)$ on profitability of Barki sheep enterprise. Deterministic biological parameters derived from the least squares analyses were used to create twelve simulated flocks. Two variables were combined factorially, the first variable was biological performance of three biological categories, (T), (M) and (B), while the second variable was the proposed annual culling rates of four rates $(10 \%, 15 \%, 20 \%$ and $30 \%)$. The twelve simulated flocks were marked by a hyphenated number, the character to the left indicating the biological category level while the digit to the right indicating the culling rate, e.g. (T/10) indicates a simulated flock of top biological performance and annual culling rate of $10 \%$ head of breeding ewes. A reasonably accurate estimate can be made using suitable assumptions based on previous management practices of the studied Barki flock. The following general assumptions were made:

- Flock size is maintained at 500 breeding ewes of different age's structure.

- Management practices of the simulated flocks were supposed to be similar to the standard practices used in the original flock.

- Ewes flock lambed once per year.

- Surplus ewe lambs and ram lambs marketed at weaning and joining ages.

- Annual mortality rate among breeding ewes $=2 \%$.

- Feed requirements of the simulated flocks were calculated according to their physiological status, and availability of feedstuff.

\section{Profit indicators}

Enterprise budget was adopted for purpose of profit determination for the twelve simulated flocks. Budget calculations were done on how costs and revenues change when annual culling rate changes under different biological category. In this context, financial data included the variable costs namely; feeds (CFM, barely, berseem and berseem hay), veterinary care, wages of permanent and hired labor in addition to purchase expenses, in case of insufficient ewe lambs available for replacement, from the market. While, revenues represent the monetary value earned from marketed surplus lambs weaned, extra ewe lambs at joining age, culled ewes, culled rams, wool (average greasy fleece weight was assumed to be $2 \mathrm{~kg} / \mathrm{head}$ ) and manure. Actual farmgate prices in Egyptian Pound (LE) for inputs and outputs prevailing in 2015 were used. Profit indicators for comparison among the twelve simulated flocks as cited by Ronald, (1981) were gross margin per ewe $(\mathrm{GM} / \mathrm{E})$ and benefit/cost ratio (B/C).

Gross margin per ewe is considered as a main determinant and a key indicator in measuring the direct effect of sheep enterprise management practices for decision maker. Major factors affecting gross margin are revenue/ewe, flock replacement costs and feeds costs. Revenue per ewe is considered a conclusive criterion determine the benefits flowing from a unit of production resources. It combines the flock biological performance, management practices and market conditions. The general equation for estimating the gross margin per ewe was: $\mathrm{GM} / \mathrm{E}=(\mathrm{R}$ - VC) divided by flock size, where; GM/E is gross margin per ewe, $\mathrm{R}$ is total revenues and $\mathrm{VC}$ is variable costs as suggested by FAO, (2002). In case of benefit/cost ratio $(\mathrm{B} / \mathrm{C})$, the flocks were ranked on 
the basis of ratio value, a ratio of 1 or more is considered viable.

\section{RESULTS AND DISCUSSION}

\section{Flocks biological characteristics}

Seasonal distributions of ELR/EJ estimates according to the current research design and dividing the 37 breeding seasons into three biological categories based on the estimated values of ELR/EJ are displayed in Figure (2). The upper curve represents the high ELR/EJ category and ranged from 0.20 to 0.33 , while the middle curve represents the moderate category and ranged from 0.12 to 0.18 , finally the lower curve represents the low ELR/EJ category of range from 0.05 to 0.10 .

Least squares overall means for the biological traits considered (EL/EJ, LB/EJ, LW/EJ, and ELR/EJ) of the three biological categories are presented in Table (1). Meanwhile, results clearly showed the category effect on the flock biological profile. Analysis of variance showed that biological category exerted a significant effect on all studied traits except that for $\mathrm{LB} / \mathrm{EJ}$ trait, no significant difference was found between (T) and (M) biological categories. The overall means obtained of the studied traits are comparable to most of estimates published and lies within the range of Barki sheep. The present overall least squares estimate for EL/EJ is closed to those reported by Ahmed (2008), Mohammady (2014) of 0.77 and Mohammady (2005) of 0.79 for Barki sheep, but is lower than those given by Salem (1990) of 0.87 and Mohammady (1999) of 0.82 for the same breed.

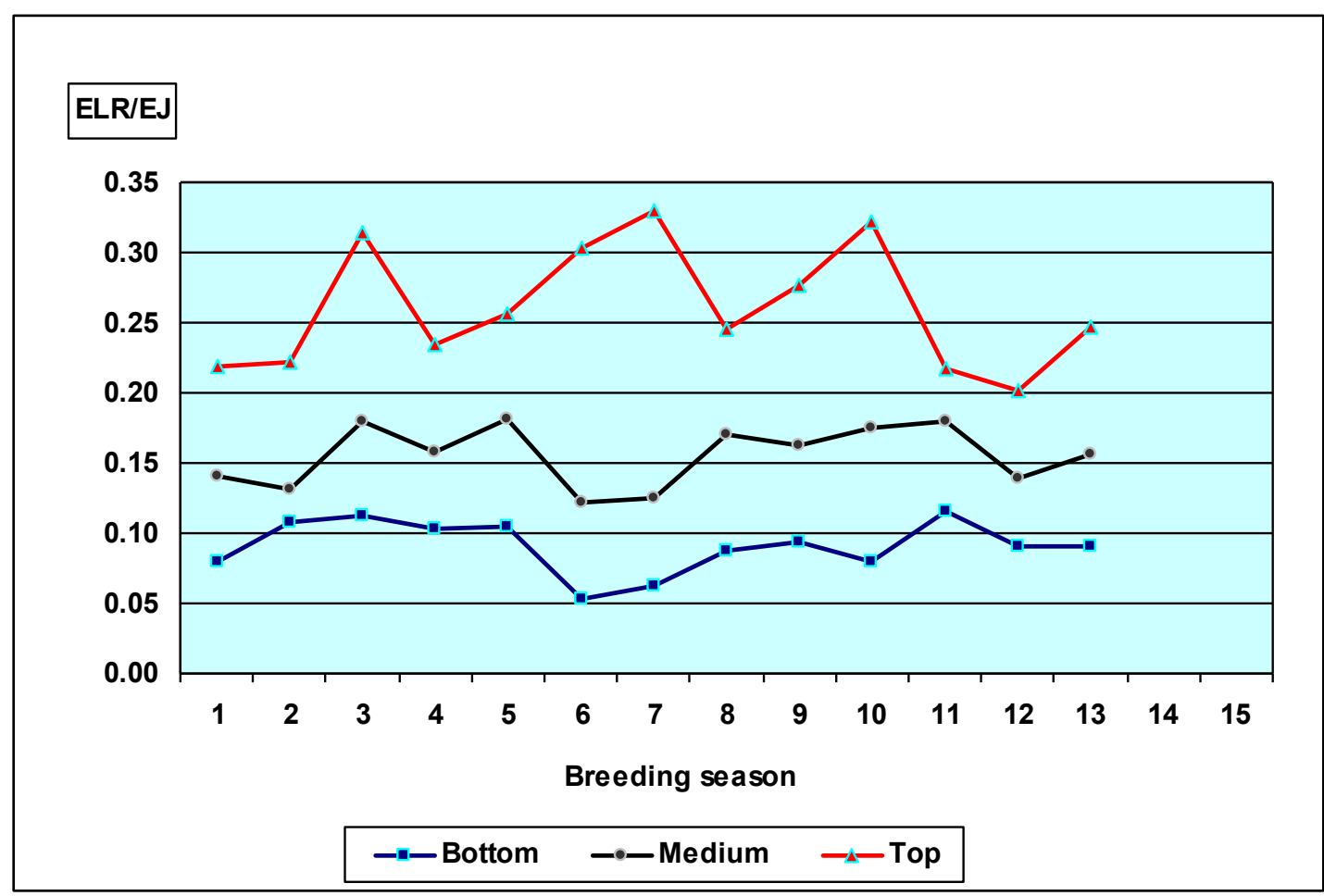

Figure 2. Seasonal distribution of ewe lambs reaching joining age per ewe joined (ELR/EJ) for the three categories

Table 1. Least squares means ( $\bar{X}$ )and standard errors (SE) of biological traits for the three biological categories

\begin{tabular}{ccccccc}
\hline \multirow{2}{*}{ Classification } & \multirow{2}{*}{$\mathbf{N}$} & \multicolumn{2}{c}{ EL/EJ } & \multicolumn{2}{c}{ LB/EJ } & \multicolumn{2}{c}{ LW/EJ } & \multicolumn{2}{c}{ ELR/EJ } \\
\cline { 3 - 6 } & & $\overline{\mathrm{X}} \pm \mathrm{SE}$ & $\overline{\mathrm{X}} \pm \mathrm{SE}$ & $\overline{\mathrm{X}} \pm \mathrm{SE}$ & $\overline{\mathrm{X}} \pm$ SE \\
\hline Overall mean & 7233 & $0.78 \pm 0.005$ & $0.81 \pm 0.005$ & $0.63 \pm 0.006$ & $0.17 \pm 0.004$ \\
Top & 2151 & $0.83^{\mathrm{a}} \pm 0.009$ & $0.86^{\mathrm{a}} \pm 0.005$ & $0.70^{\mathrm{a}} \pm 0.010$ & $0.26^{\mathrm{a}} \pm 0.009$ \\
Medium & 2577 & $0.80^{\mathrm{b}} \pm 0.009$ & $0.84^{\mathrm{a}} \pm 0.009$ & $0.63^{\mathrm{b}} \pm 0.010$ & $0.16^{\mathrm{b}} \pm 0.007$ \\
Bottom & 2505 & $0.72^{\mathrm{c}} \pm 0.009$ & $0.75^{\mathrm{b}} \pm 0.010$ & $0.57^{\mathrm{c}} \pm 0.010$ & $0.09^{\mathrm{c}} \pm 0.006$ \\
\hline
\end{tabular}

EL/EJ, number of ewes lambing per ewe joined: LB/EJ, number of lambs born per ewe joined; LW/EJ, number of lambs weaned per ewe joined; ELR/EJ, number of ewe lambs reaching joining age per ewe joined. ${ }^{\mathrm{a}, \mathrm{b}, \mathrm{c}}$ Means with different superscript in the same column are significantly different $(\mathrm{P}<0.01)$.

The results also showed that $\mathrm{LB} / \mathrm{EJ}$ estimate is almost close to those reported by Ahmed (2008) and Mohammady (2014) of 0.80, however, higher than those reported by Bedier (1987) of 0.63 and Younis et al. (1984) of 0.79 for the same breed. In the same context, the overall mean of $\mathrm{LW} / \mathrm{EJ}$ is close to that cited by Mohammady (2014) of 0.62 and higher than those reported by Bedier (1987) of 0.59 and Ahmed et al., (1992) of 0.54 for Barki breed. On the other 
hand, the estimated overall mean of ELR/EJ is lower than that reported by Mohammady (2005) of 0.275.

Furthermore, when applying the proposed culling rates, it is worthy to note that, as shown in Table (2), most estimates of biological traits of the same biological category were improved due to culling procedures up to $20 \%$ culling rate, then declined when reached $30 \%$. This may be due to culling an extra number of old ewes from the flock, in spite of they are still productive, and replaced by freshening ewe lambs which are still of low productivity in order to keep balanced flock age structure,. Moreover, analysis of variance showed evidence that culling rate effect showed no significant effect on ELR/EJ among flocks of the same biological category, while exerted significant differences on all traits among the biological categories.

\section{Budget breakdown}

The obtained least squares means of the biological traits for the twelve simulated flocks were transformed into equivalent numbers of flock structure based on flock size as shown in Table (3). The current flock structure declared that sales of culled ewes were 50, 75, 100 and 150 ewes, according to the four proposed annual culling rates $10 \%$. $15 \%$. $20 \%$ and $30 \%$, respectively. While, numbers of ewe lambs required for replacement to retain the flock size of 500 breeding ewes were 60 , 85,110 and 160 ewes, respectively (considering 2\% annual mortality for breeding ewes). Concerning sales, Table (3) showed that some of ewe lambs were sold at weaning age and the surplus at joining age. Therefore, the expected revenues generated and required variable costs were calculated on the basis of the monetary value of the surplus ewe lambs marketed at both ages, in addition to other sources of revenues $(\mathrm{FAO}, 2002)$

Table 2. Least squares means $(\bar{X})$ and standard errors (SE) of biological traits for the three categories under proposed culling rates

\begin{tabular}{|c|c|c|c|c|c|}
\hline \multirow{2}{*}{ Simulated flocks } & \multirow{2}{*}{$\mathbf{N}$} & EL/EJ & LB/EJ & LW/EJ & ELR/EJ \\
\hline & & $\overline{\mathrm{X}} \pm \mathrm{SE}$ & $\overline{\mathrm{X}} \pm \mathrm{SE}$ & $\overline{\mathrm{X}} \pm \mathrm{SE}$ & $\overline{\mathrm{X}} \pm \mathrm{SE}$ \\
\hline Top: & 2151 & & & & \\
\hline $10 \%$ & 1936 & $0.88^{\mathrm{a}} \pm 0.007$ & $0.91^{\mathrm{a}} \pm 0.009$ & $0.78^{\mathrm{a}} \pm 0.010$ & $0.29^{\mathrm{a}} \pm 0.010$ \\
\hline $15 \%$ & 1828 & $0.90^{\mathrm{a}} \pm 0.007$ & $0.92^{\mathrm{a}} \pm 0.008$ & $0.83^{\mathrm{a}} \pm 0.010$ & $0.30^{\mathrm{a}} \pm 0.011$ \\
\hline $20 \%$ & 1721 & $0.93^{\mathrm{a}} \pm 0.006$ & $0.96^{\mathrm{a}} \pm 0.008$ & $0.88^{\mathrm{a}} \pm 0.009$ & $0.32^{\mathrm{a}} \pm 0.011$ \\
\hline $30 \%$ & 1549 & $0.93^{\mathrm{a}} \pm 0.006$ & $0.95^{\mathrm{a}} \pm 0.008$ & $0.85^{\mathrm{a}} \pm 0.009$ & $0.32^{\mathrm{a}} \pm 0.011$ \\
\hline Medium & 2577 & & & & \\
\hline $10 \%$ & 2319 & $0.85^{b} \pm 0.007$ & $0.89^{a} \pm 0.009$ & $0.70^{b} \pm 0.106$ & $0.18^{\mathrm{b}} \pm 0.008$ \\
\hline $15 \%$ & 2190 & $0.87^{\mathrm{b}} \pm 0.007$ & $0.91^{\mathrm{a}} \pm 0.009$ & $0.75^{b} \pm 0.105$ & $0.19^{\mathrm{b}} \pm 0.009$ \\
\hline $20 \%$ & 2080 & $0.85^{b} \pm 0.007$ & $0.92^{\mathrm{b}} \pm 0.009$ & $0.79^{b} \pm 0.103$ & $0.20^{\mathrm{b}} \pm 0.009$ \\
\hline $30 \%$ & 1804 & $0.87^{b} \pm 0.007$ & $0.91^{\mathrm{a}} \pm 0.009$ & $0.76^{\mathrm{b}} \pm 0.104$ & $0.20^{\mathrm{b}} \pm 0.007$ \\
\hline Bottom & 2505 & & & & \\
\hline $10 \%$ & 2254 & $0.78^{c} \pm 0.009$ & $0.81^{\mathrm{b}} \pm 0.010$ & $0.64^{\mathrm{c}} \pm 0.011$ & $0.10^{\mathrm{c}} \pm 0.006$ \\
\hline $15 \%$ & 2129 & $0.80^{c} \pm 0.009$ & $0.84^{\mathrm{b}} \pm 0.010$ & $0.68^{c} \pm 0.011$ & $0.11^{\mathrm{c}} \pm 0.007$ \\
\hline $20 \%$ & 2023 & $0.83^{c} \pm 0.008$ & $0.86^{\mathrm{c}} \pm 0.010$ & $0.71^{c} \pm 0.011$ & $0.11^{\mathrm{c}} \pm 0.007$ \\
\hline $30 \%$ & 1753 & $0.81^{\mathrm{c}} \pm 0.009$ & $0.84^{\mathrm{b}} \pm 0.010$ & $0.67^{\mathrm{c}} \pm 0.011$ & $0.11^{\mathrm{c}} \pm 0.006$ \\
\hline
\end{tabular}

EL/EJ, number of ewes lambing per ewe joined: LB/EJ, number of lambs born per ewe joined; LW/EJ, number of lambs weaned per ewe joined; ELR/EJ, number of ewe lambs reaching joining age per ewe joined. ${ }^{a, b, c}$ Means with different superscript in the same column are significantly different $(\mathrm{P}<0.01)$.

Table 3. Flock structure of the twelve simulated flocks based on biological performance and proposed annual culling rates

\begin{tabular}{lcccccccccccc}
\hline \multirow{2}{*}{ Flock structure } & \multicolumn{4}{c}{ Top } & \multicolumn{1}{c}{ Medium } & \multicolumn{3}{c}{ Bottom } \\
\cline { 2 - 13 } & $\mathbf{1 0 \%}$ & $\mathbf{1 5 \%}$ & $\mathbf{2 0 \%}$ & $\mathbf{3 0} \%$ & $\mathbf{1 0 \%}$ & $\mathbf{1 5 \%}$ & $\mathbf{2 0 \%}$ & $\mathbf{3 0 \%}$ & $\mathbf{1 0 \%}$ & $\mathbf{1 5 \%}$ & $\mathbf{2 0 \%}$ & $\mathbf{3 0 \%}$ \\
\hline Ewe lambed & 440 & 450 & 465 & 463 & 425 & 435 & 425 & 436 & 390 & 400 & 415 & 404 \\
Lambs born & 455 & 460 & 480 & 473 & 45 & 455 & 460 & 453 & 405 & 420 & 430 & 419 \\
lambs weaned & 390 & 415 & 440 & 428 & 350 & 375 & 395 & 380 & 320 & 340 & 355 & 383 \\
ELR & 145 & 150 & 160 & 159 & 90 & 95 & 100 & 99 & 50 & 55 & 55 & 54 \\
EL required & 60 & 85 & 110 & 160 & 60 & 85 & 110 & 160 & 60 & 85 & 110 & 160 \\
\hline Sales: & & & & & & & & & & & & \\
$\quad$ Culled rams & 12 & 12 & 12 & 12 & 12 & 12 & 12 & 12 & 12 & 12 & 12 & 12 \\
Culled ewes & 50 & 75 & 100 & 150 & 50 & 75 & 100 & 150 & 50 & 75 & 100 & 150 \\
$\quad$ Ram lambs & 180 & 193 & 205 & 199 & 160 & 173 & 183 & 175 & 145 & 155 & 163 & 154 \\
Ewe lambs: & & & & & & & & & & & & \\
$\quad$ Weaning age & 33 & 40 & 41 & 36 & 74 & 82 & 87 & 79 & 104 & 108 & 116 & 109 \\
$\quad$ Joining age & 85 & 65 & 50 & ---- & 30 & 10 & ---- & --- & ---- & ---- & ---- & ---- \\
\hline Total sales & $\mathbf{3 6 0}$ & $\mathbf{3 8 5}$ & $\mathbf{4 0 8}$ & $\mathbf{3 9 7}$ & $\mathbf{3 2 6}$ & $\mathbf{3 5 2}$ & $\mathbf{3 8 2}$ & $\mathbf{4 1 6}$ & $\mathbf{3 1 1}$ & $\mathbf{3 5 0}$ & $\mathbf{3 9 1}$ & $\mathbf{4 2 5}$ \\
\hline
\end{tabular}

ELR; ewe lambs reaching joining age, EL; ewe lambs. 
Revenues breakdown of the twelve simulated flocks are displayed in Figure (3). Results revealed that simulated flock $(\mathrm{T} / 20)$ had higher revenues generated than the corresponding one of the other three simulated flocks. The high revenues were mainly due to the improvement of all biological traits that reached the highest estimates at $20 \%$ culling rate. As a result of that, the total marketed animals were (408) heads, which exceeded the other three simulated flocks as shown in Table (3). Moreover, the main source of revenues was generated mainly from ram lambs crop which constituted about $42 \%$ of the total revenues, while Nunez and Moyano reported higher estimates of $71 \%$ and $56 \%$ for top and bottom flocks, respectively.

On the other hand, simulated flock $(\mathrm{M} / 30)$ earned the highest revenues among the other simulated flocks of the same category. This is mainly due to the higher numbers of sold animals (416 heads) than those of the other three flocks. The major component of revenues was sourced mainly from culled ewes which represent $46 \%$ of the flowing revenues. The same trend was observed in case of simulated flock $(\mathrm{B} / 30)$, and culled ewes represented the main source of the total revenues and accounted for $45 \%$. Revenues breakdown of the current research revealed that contributions of the major sources of revenues were differed from one simulated flock to another depending upon biological performance category and annual culling rate. These results are in disagreement with Jason (1998) who reported that, there is no statistically significant correlation between production level and culling rate.

In general, variable costs breakdown of the current research showed that feeding components costs constituted the major expenses as shown in Figure (4). Simulated flock (T/30) accounted for some increase of (CFM) offered mainly to pregnant and lactating ewes, which would be associated with extra numbers of ewes lambed and accounted for $48 \%$ of the total variable costs. As well as, simulated flocks $(\mathrm{M} / 30)$ and $(\mathrm{B} / 30)$ scored the highest expenses among their both categories. These extra expenses were mainly due to (CFM) expenses and purchase ewe lambs for replacement. From biological point of view, in medium and bottom categories flocks, producers have inadequate numbers of ewe lambs for replacement to maintain flock size, therefore they forced to spend extra expenses to purchase ewe lambs required from the market which selected on their phenotypic appearance only as mentioned by Gottstein (2009).

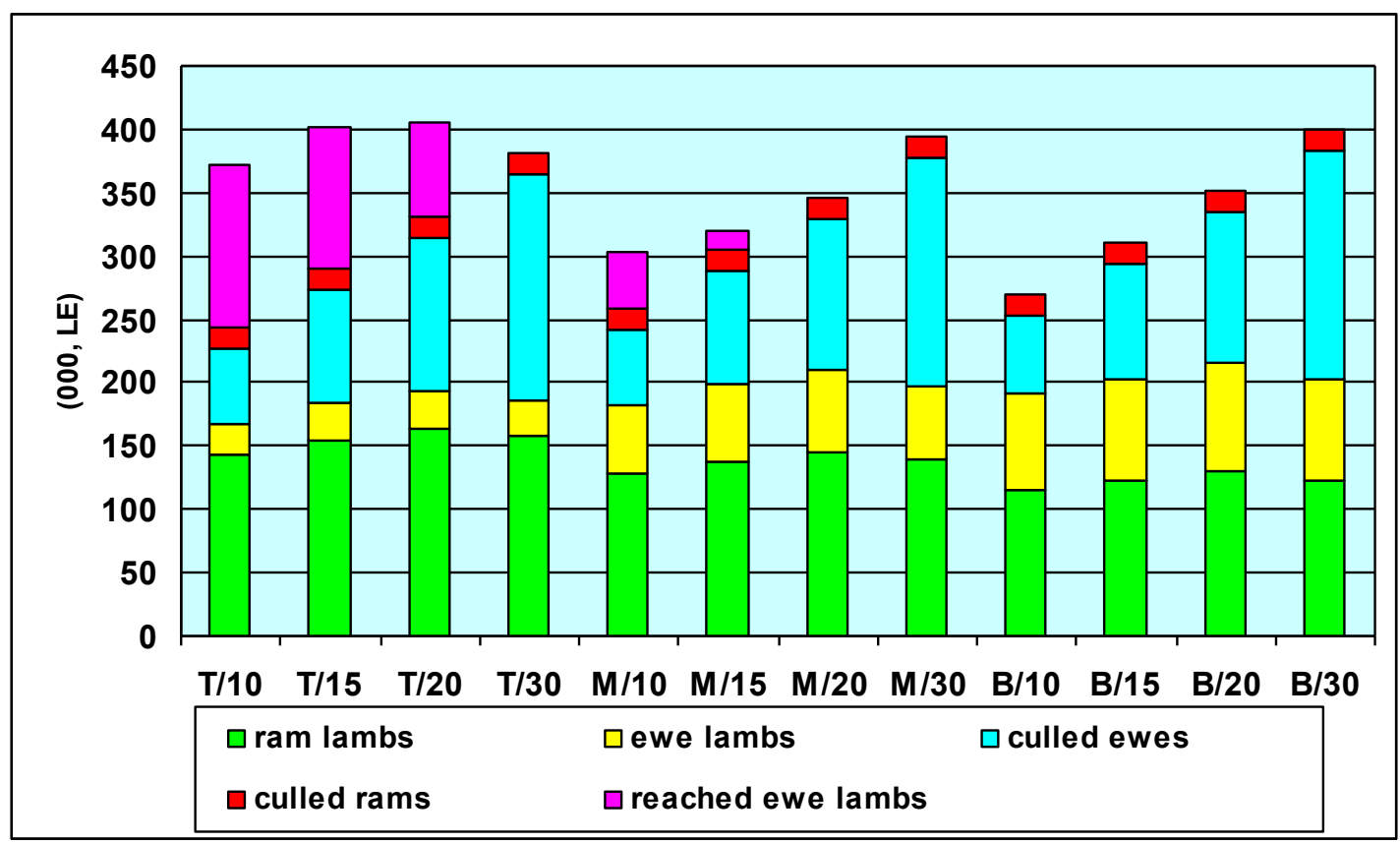

Figure 3. Revenues breakdown of the studied twelve simulated flocks 


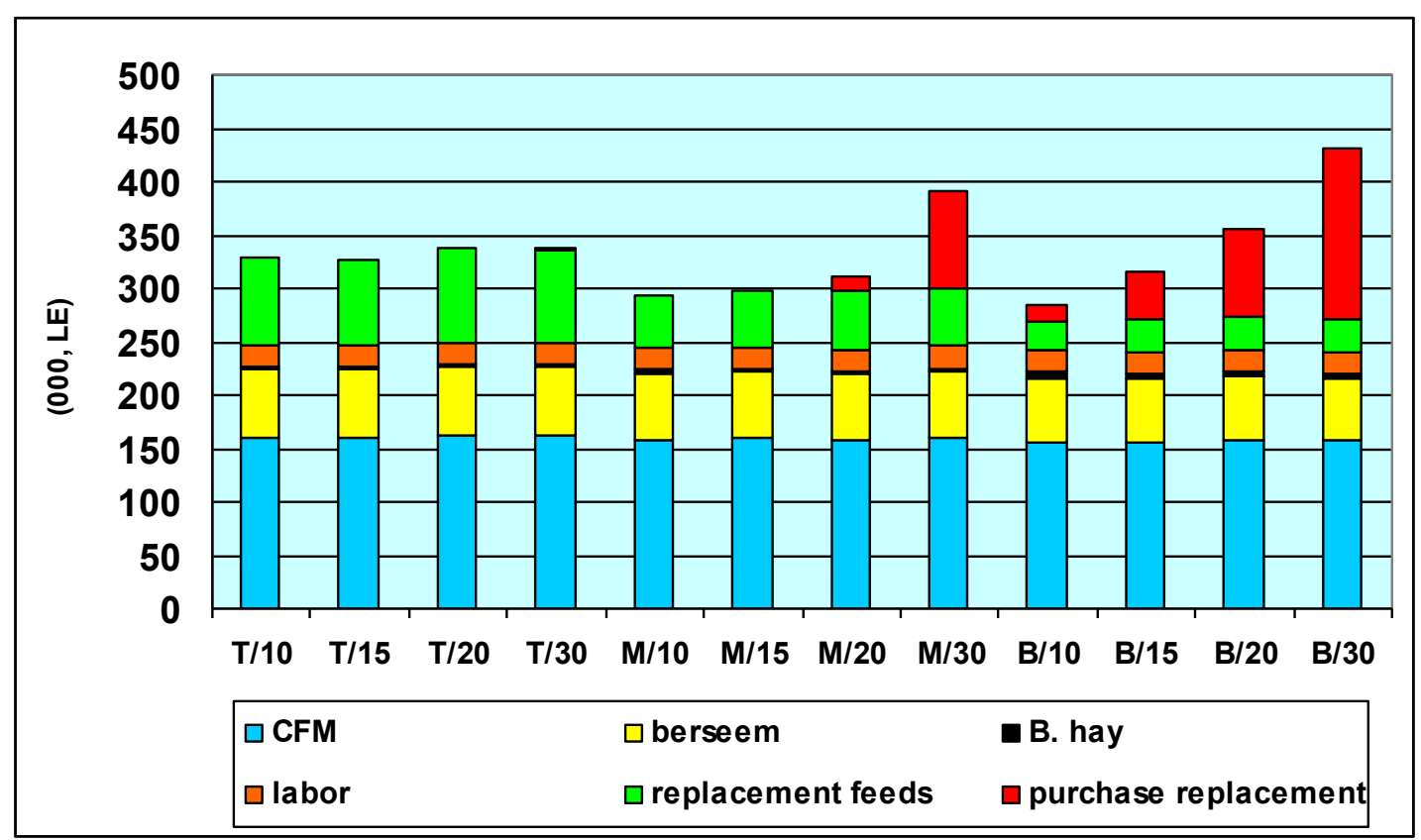

Figure 4. Variable costs breakdown of the studied twelve simulated flocks

\section{Profit indicators:}

Results of economical indicators derived from the current enterprise budget are presented in Table (4). From economic point of view, simulated flock (T/20) achieved the highest revenue per ewe among the other $(\mathrm{T})$ flocks. While, simulated flocks $(\mathrm{M} / 30)$ and $(\mathrm{B} / 30)$ were the highest among the corresponding flocks. These results are due to that these flocks marketed more animals than the other flocks (408, 416 and 425, respectively) as shown in Table (3). On the other side, the same trend was observed in case of variable costs involved; the same three simulated flocks spent the highest variable costs among the relevant flocks, these may be due to extra feeds and replacement costs.

On the other hand, benefit/cost ratio clearly indicates the relation between variable costs spent to convert the biological performance into benefits earned from the flock. The current $\mathrm{B} / \mathrm{C}$ ratios, as shown in Table (4), revealed that simulated flock (T/15) achieved the highest ratio of 1.25 , which is lower than that reported by Ahmed (2008) of 1.58 for Barki breed. On the contrary, the four bottom simulated flocks, which characterized by low biological performance level, each unit of money spent rewarded only $0.98,1.01,1.02$ and 0.95 , respectively, which are higher than that reported by Ahmed (2008) of 0.73 .
Estimates of $\mathrm{GM} / \mathrm{E}$ for the twelve simulated flocks are displayed in Figure (5). All the current simulated flocks generated positive GM/E except those simulated flocks $(\mathrm{B} / 10)$ and $(\mathrm{B} / 30)$ which scored negative estimate. The results showed that (T/15) flock achieved the highest gross margin/ewe of LE 173 among all the studied flocks. The obtained GM is higher than that reported by Ahmed (2008) of LE 167.6 for the same breed. However, it is of interest to notice that, in spite of $(B / 10$ and $B / 30)$ flocks generated high revenues, as shown in Figure (3), nevertheless, revenues could not compensate the extra expenses needed to purchase replacement ewe lambs and recorded negative gross margin of LE -12 and LE -43 , respectively. This could be attributed to low biological performance of (B) simulated flocks, which is characterized by fewer numbers of ewe lambs available for replacement and/or for sale (Table 2). These results are in agreement with that reported by Nunez and Moyano (2006) who cited that the top biological performance flock can be considered profitable, while the bottom one have a negative economic balance. The current findings revealed the importance and significant mutual relation between the biological performance of the flock and practiced annual culling rate.

Table 4. Economical indicators per ewe of the twelve simulated flocks in (LE)

\begin{tabular}{lcccccccccccc}
\hline \multirow{2}{*}{ Criteria } & \multicolumn{1}{c}{ Top } & \multicolumn{1}{c}{ Medium } & \multicolumn{1}{c}{ Bottom } \\
\cline { 2 - 15 }$y$ & $10 \%$ & $20 \%$ & $30 \%$ & $10 \%$ & $15 \%$ & $20 \%$ & $30 \%$ & $10 \%$ & $15 \%$ & $20 \%$ & $30 \%$ \\
\hline Revenues & 817 & 878 & 884 & 837 & 681 & 713 & 767 & 862 & 611 & 693 & 777 & 873 \\
Variable costs & 710 & 705 & 728 & 728 & 640 & 648 & 678 & 835 & 623 & 685 & 764 & 915 \\
Gross margin & 107 & 173 & 156 & 109 & 40 & 65 & 88 & 26 & -12 & 7 & 13 & -43 \\
B/C ratio & 1.15 & 1.25 & 1.26 & 1.15 & 1.06 & 1.10 & 1.13 & 1.03 & 0.98 & 1.01 & 1.02 & 0.95 \\
\hline
\end{tabular}




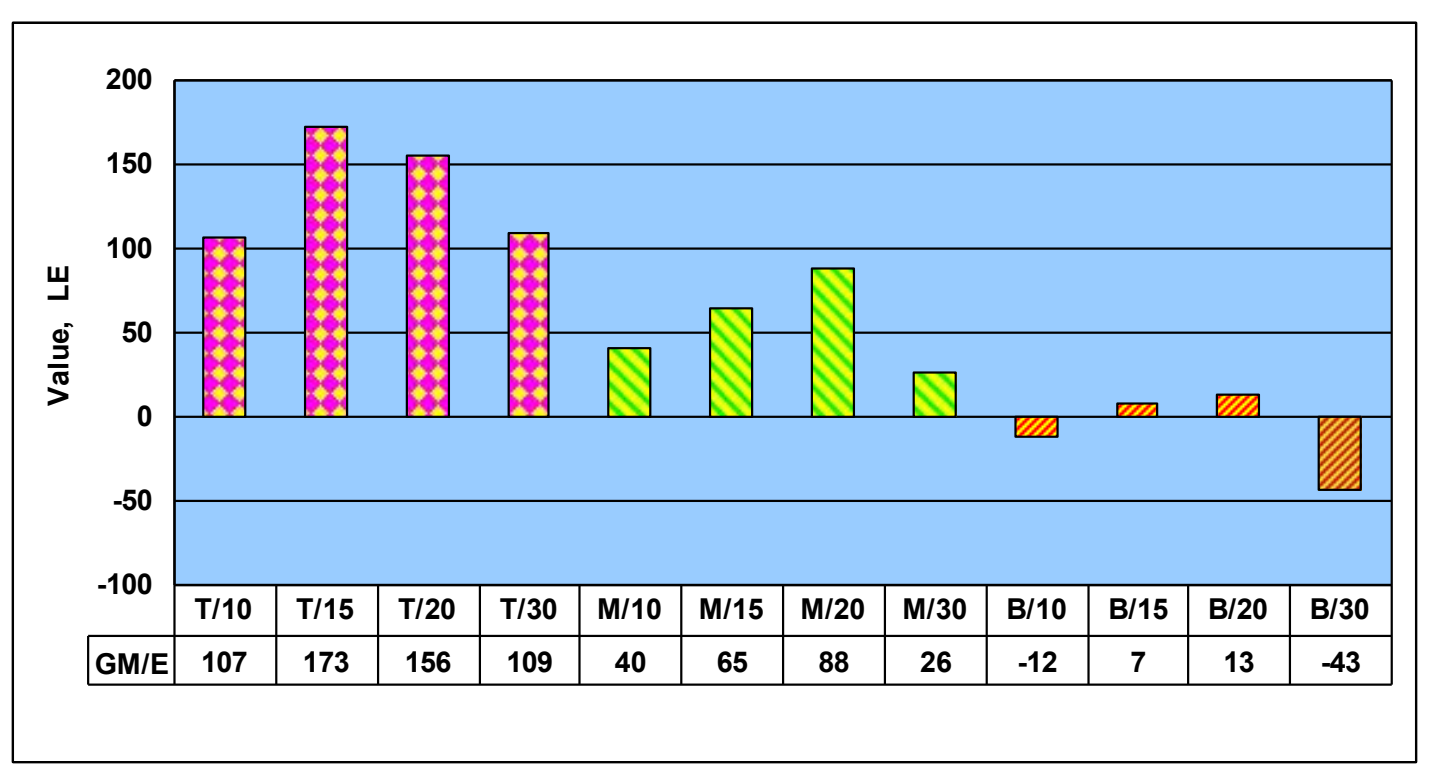

Figure 5. The expected gross margin per ewe of the twelve simulated flocks

\section{CONCLUSION}

The attained results highlight the significant bioeconomic relation between biological performance of the flock and culling rate which plays an important role in sheep enterprise profitability. The current findings indicate that there is a considerable scope for sheep producers to improve profits of their Barki sheep enterprise by refining culling rate. It could be concluded that, increasing revenues does not means improving profit but variable cost is probably the decisive factor affecting financial benefits of sheep enterprise and its impact on enterprise profitability. Furthermore, from the economic point of view, it is of interest to conclude that, under the prevailing market price of inputs and outputs, the current research revealed the guidelines for the profitable annual culling rate for Barki breed enterprises of different biological performance categories and recommended the optimal annual culling rate of $15 \%$ for (T) flock, while $20 \%$ for (M) and (B) flocks under semi-arid conditions of Egypt.

\section{ACKNOWLEDGMENT}

The author expresses her sincere appreciation to the Animal Breeding Unit, Department of Animal Breeding of Desert Research Center for supporting and providing breeding flock data.

\section{REFERENCES}

Ahmed, A.M., 2008. Technical and financial analysis of Barki sheep under semi-intensive production system. Egyptian J. Anim. Prod., 45 (1):25-34.

Ahmed, A.M., E.S.E. Galal, A.A. Younis, 1992. Estimates of productive and reproductive performances of commercial flock of Barki sheep. Egyptian J. Anim. Prod., 29:109-122.
Barnard, C.S., J.S. Nix, 1993. Farm Planning and Control, $2^{\text {nd }}$ Edition. Cambridge University Press, Cambridge.

Bedier, N.Z., 1987. A study on optimum ewe size under desert conditions. Ph.D. Thesis. Faculty of Agriculture, Ain-Shams University, Cairo. Pp 120.

Gottstein, M., 2009. Sheep Farm Management Notes: Planning your replacement policies - what are the options ?. website, http://europa.eu.

Jason, K., 1998. Culling rate and profit. Is there a management issue? https:/ecommons. Cornell.edu//bitstream. http://hdl.handle./1813136887.

Mohammady, M.I., 1999. Biological efficiency of sheep and goat production. M.Sc. Thesis, Faculty of Agriculture, Cairo University. Pp126.

Mohammady, M.I., 2005. Flock dynamics of desert Barki sheep in relation to age structure. Ph.D. Thesis, Faculty of Agriculture, Cairo University. Pp 203

Mohammady, M.I., 2014. Influence of flock size and biological performance on economic efficiency of Barki sheep under semi-arid conditions in Egypt. Journal of American Science. 10 (3s): 73-79.

NRC, 2007. Nutrient requirements of small ruminants. National Academy of Science, National Research Council, Washington, DC, USA.

Nunez, C., F.J. Moyano, 2006. Productive and economic parameters in semi - intensive sheep flocks in the west of La Culebra (Zamora) Options Mediterraneennes, Serie A, No. 70, p 165- 170.

Ronald, D.K., 1981. Farm Management. McGrawHill Book Company, New York.

Salem, H.A., 1990. A study on the frequency of lambing in relation to productivity in Barki sheep. M.Sc. Thesis, Faculty of Agriculture, Al-Azhar University, Cairo, Egypt. 
SAS, 2004. User's guide, 6.03 Edition, Statistical Analysis System Institute Inc. Cary NC 275118000, USA.

Turner, H.N., G.H. Brown, G.H. Ford, 1968. The influence of age structure on total productivity in breeding flock of Merino sheep. 1. Flocks with a fixed number of breeding ewes, producing their own replacement. Aust. J. Agric. Res., 19: 443745.

Younis, A.A., M.M. Abdel-Aziz, E.A. Afifi, M. Khaiery, 1984. Biological efficiency of meat production in Barki sheep. World Rev. of Anim. Prod. XX, (4): 1-37.

معدلات الاستبعاد المربحة لقطيع الأغنام البرقى المرباة تحت الظروف شبة الجافة بمصر

منى محمدى ابراهيم

شعبة الإنتاج الحيوانى واللدواجن، مركز بحوث الصحراء، القاهرة، مصر

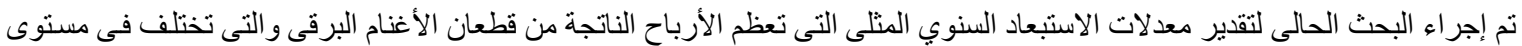

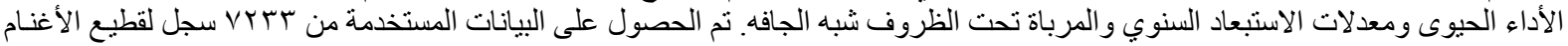

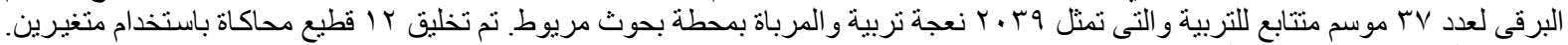

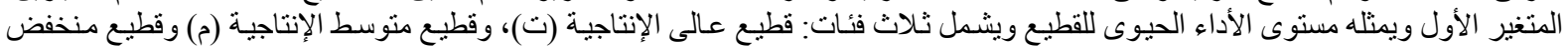

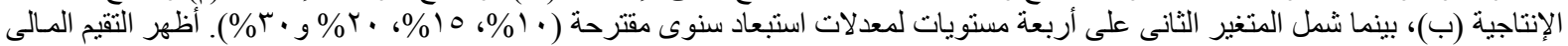

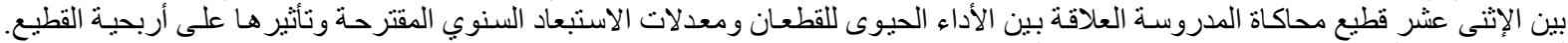

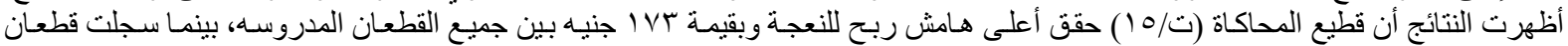

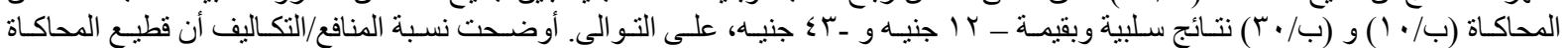

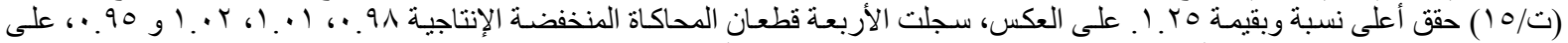

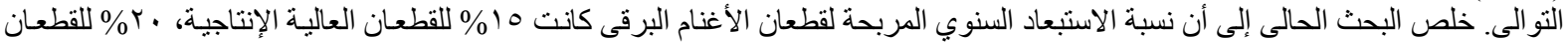

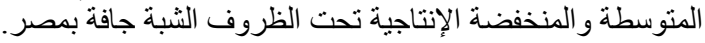

